\title{
Application of Response Surface Modeling and Chemometrics Methods for the Determination of Ofloxacin in Human Urine Using Dispersive Liquid-Liquid Microextraction Combined with Spectrofluorimetry
}

\author{
Farah Assadian and Ali Niazi* \\ Department of Chemistry, Arak Branch, Islamic Azad University, 14757 Arak, Iran

\begin{abstract}
Dispersive liquid-liquid microextraction (DLLME) and spectrofluorimetry, coupled with chemometrics methods, are proposed in this work for the pre-concentration and determination of ofloxacin concentration in spiked human urine. Chloroform and acetonitrile were selected as the extraction and dispersive solvents by the one-variable-at-a-time process. The Box-Behnken design was used to optimize the other variables, including the volume of extraction and dispersion solvents, solution $\mathrm{pH}$, and ionic strength. A linear calibration curve was obtained in the 5.0-120.0 $\mathrm{ng} \mathrm{mL}^{-1}$ range under optimal conditions with a detection limit of $1.61 \mathrm{ng} \mathrm{mL}^{-1}$ and correlation coefficient of 0.9948. A relative standard deviation (RSD) of $1.13 \%$ was obtained for seven consecutive replicates. Parallel factor analysis (PARAFAC) and partial least square (PLS) modeling were applied for the multivariate calibration of the spectrofluorimetric data. To pre-process the data matrices and predict the model results, the orthogonal signal correction (OSC) was used, and the analysis results were statistically compared. The methods accuracy values for ofloxacin determination, evaluated by the root mean square errors of prediction (RMSEP) and relative standard error of prediction (RSEP), were 0.82 and 1.12 using OSC-PLS, and 0.31 and 0.42 using OSC-PARAFAC models, respectively. Ofloxacin can be reliably determined in human urine samples through the proposed procedure, according to the results.
\end{abstract}

Keywords: ofloxacin, dispersive liquid-liquid microextraction, spectrofluorimetry, BoxBehnken design, OSC-PARAFAC

\section{Introduction}

A second-generation fluoroquinolone, ofloxacin (OFL, 9-fluoro-2,3-dihydro-3-methyl-10-(4-methyl1 - piperazine)- 7 - oxo- $7 \mathrm{H}$-pyrido[ $1,2,3$-de]1,4-benzoxazine-6-carboxylic acid) is a synthetic antibiotic of the fluoroquinolone drug family (Figure 1). ${ }^{1}$ This antibacterial agent is widely used in the treatment of the respiratory tract, urinary tract, and tissue-based infections due to gram-positive and gram-negative bacteria. ${ }^{2}$ Bacteria multiplication is prevented by ofloxacin through the inhibition of the reproduction and repair of genetic material (DNA). Ofloxacin is also available for topical use, in the form of eye and ear drops. Monitoring OFL concentrations in real samples is vital for adjusting the drug dosage and studying drug-drug interactions. ${ }^{3}$

High-performance liquid chromatography (HPLC), ${ }^{4-6}$ spectrophotometry, ${ }^{7,8}$ spectrofluorimetry, ${ }^{9,10}$ thin layer chromatography (TLC)-fluorescence

*e-mail: a-niazi@iau-arak.ac.ir, ali.niazi@gmail.com<smiles>CC1COc2c(N3CCN(C)CC3)c(F)cc3c(=O)c(C(=O)O)cn1c23</smiles>

Figure 1. Chemical structure of ofloxacin.

spectrodensitometry,,$^{11,12}$ capillary electrophoresis, ${ }^{13,14}$ and flow-injection chemiluminescence ${ }^{15,16}$ are several methods used for ofloxacin determination. Some of these methods are expensive, elaborate, and often not sensitive enough to directly determine trace amounts of ofloxacin in urine samples. Thus, a pre-concentration step is required.

As first reported by Assadi and co-workers ${ }^{17}$ in 2006, dispersive liquid-liquid microextraction (DLLME) can overcome some of the mentioned constraints due to its advantages, including simplicity of operation, speed, low cost, high recoverability, and high enrichment factor. An appropriate mixture of the extraction and disperser solvents is rapidly injected via syringe into the aqueous 
samples containing the analytes in DLLME, yielding a cloudy solution created by the formation of fine droplets of the extraction solvent dispersed in the sample solution. This cloudy solution is then centrifuged to precipitate the fine droplets at the bottom of the conical test tube. Instrumental analysis is used to determine the analyte in the precipitate..$^{18-23}$

The impacts of different experimental parameters were investigated and the optimized method was successfully used for the real urine sample analysis done in this work. In this approach, a chemometric study of the optimization of DLLME parameters has been carried out in order to determine ofloxacin.

The Box-Behnken experimental design under response surface methodology (RSM) was used to study and optimize the effective parameters on the extraction recovery. ${ }^{24-27}$ The Box-Behnken design (BBD) includes all spherical designs and requires factors to be run at only three levels. The designs are also fully or nearly rotatable. In addition, these designs do not contain combinations for all factors at their highest or lowest levels simultaneously. Thus, the BBD could reduce the number of required experiments and is useful in avoiding experiments performed under extreme conditions, which may yield unsatisfactory results. ${ }^{28} \mathrm{RSM}$ is a set of statistically useful methods for the design of experiments, building of models, and analysis of the effects of independent factors on the response. It can be used in the evaluation of the relative significance of several affecting factors. The determination of the optimal operational conditions for desirable responses is the main objective of RSM. ${ }^{29}$

Considering the accessibility of digitized spectroscopic data, the application of quantitative chemometrics methods to multivariate chemical data is becoming increasingly widespread. Multivariate optimizing methods are superior to most common optimization methods, since more information could be obtained by carrying out fewer experiments; the interactions are found among the variables in these methods. To increase the selectivity in the determination of real samples, the partial least squares (PLS) method is used as a multivariate calibration. Some samples are required by the PLS method to make models as the calibration set. The PLS method validates the samples using a validation set. The component concentration is determined by the results of the calibration from the sample spectrum. The basic concept of PLS and its application in quantitative determinations have already been explained. ${ }^{30-34}$

The investigation of $\mathrm{N}$-dimensional (or $\mathrm{N}$-way or $\mathrm{N}$-mode) data arrays has been of great interest because of the sophisticated experimental designs and the increased amount of data originating from modern instrumentation. Collection of data tables with a fixed set of objects and variables under different experimental conditions may be used to generate three-dimensional arrays. A multi-way method originating from psychometrics is the parallel factor analysis (PARAFAC) ${ }^{35}$ PARAFAC is gaining more interest in chemometrics and the corresponding areas due to factors like simply increased information regarding the method and its possibilities, the increased complexity of the corresponding data in science and industry, and the increased computational power. PARAFAC, one of several decomposition methods for $\mathrm{N}$-way data, is a generalization of the principal component analysis (PCA) ${ }^{36}$ to higher orders. Orthogonal signal correction (OSC), applied as a pre-processing step, improves the calibration model by filtering strong structured changes in the spectra not associated with the concentration. ${ }^{37-44}$

The extraction and determination of ofloxacin in human urine were done through DLLME and spectrofluorimetry in the present work. The effect of important variables such as type and volume of extraction and dispersive solvents, $\mathrm{pH}$, and sample ionic strength was investigated and optimized by BBD. The PLS and PARAFAC calibration were applied in the quantification of ofloxacin, while OSC was used in the pre-processing of data matrices. The accuracy of the methods was evaluated through the root mean square errors of prediction (RMSEP) and relative standard error of prediction (RSEP).

\section{Experimental}

\section{Reagents and material}

All the reagents and chemicals used in this work were of analytical reagent grade. Ofloxacin was purchased from Sigma-Aldrich Chemical Co. Universal solution as buffer, carbon tetrachloride, dichloromethane, chloroform, nitrobenzene, methanol, ethanol, acetonitrile, and acetone were supplied by Merck Chemical Co. A total of $1000 \mu \mathrm{g} \mathrm{mL}^{-1}$ of stock standard solution of ofloxacin was prepared by dissolving the compound in sodium hydroxide, followed by dilution with double distilled deionized water. This solution was stored in the dark at $4{ }^{\circ} \mathrm{C}$.

Instrumentation and software

A PerkinElmer, LS 45 Spectrofluorimeter enhanced by $150 \mathrm{~W}$ Xe lamp, which was coupled to a computer and equipped with a $300 \mu \mathrm{L}$ quartz microcell, was used for recording the spectra using Windows 7 operating system. All the measurements were done at the exciting 
wavelength of 200-350 nm for every $10 \mathrm{~nm}$, and at the emission wavelength in the 400-650 $\mathrm{nm}$ range for every $1 \mathrm{~nm}$. A centrifuge (Sigma) was used to accelerate the phase separation process. The $\mathrm{pH}$ was determined with a 780 Metrohm digital $\mathrm{pH}$ meter with a combined glass-calomel electrode. The BBD was run in Minitab version 16. The programs for PLS, PARAFAC, and OSC calculation were written in MATLAB 2012 and run on a personal computer (CPU $3.0 \mathrm{GHz}$ and RAM $4 \mathrm{~GB}$ ) equipped with the Windows XP operating system. The applied OSC version is based on the Wold et al. ${ }^{45}$ algorithm.

\section{Experimental procedure}

A standard solution containing $5.0-120.0 \mathrm{ng} \mathrm{mL}^{-1}$ of ofloxacin $(10 \mathrm{~mL})$ was poured in a sealed conical-bottom tube and the solution $\mathrm{pH}$ was adjusted to 4.5 using a universal buffer. A mixture of acetonitrile $(600 \mu \mathrm{L})$ and chloroform $(300 \mu \mathrm{L})$, dispersive and extraction solvent, respectively, was then rapidly injected into the sample using a $2 \mathrm{~mL}$ syringe. A cloudy solution formed, which contained tiny dispersed chloroform drops; ofloxacin was extracted into the droplets. The tiny chloroform drops precipitated at the bottom of the conical tube (around $220 \mu \mathrm{L}$ ) after centrifugation for 10 minutes at $4,000 \mathrm{rpm}$. The upper aqueous solution was removed and the precipitated phase was transferred into a $300 \mu \mathrm{L}$ microcell using a syringe for spectrofluorimetric measurement.

\section{Real samples preparation before DLLME}

Samples containing $10 \mathrm{~mL}$ of urine and serum were collected from 25-30 year old healthy volunteers to validate the proposed method. The samples were transferred into centrifuge tubes and centrifuged at 3,500 rpm for five min. Then, $2 \mathrm{~mL}$ of the clear supernatant was poured into a new centrifuge tube and the $\mathrm{pH}$ was adjusted to 4.5 , followed by spiking with standard 5.0-120.0 $\mathrm{ng} \mathrm{mL}^{-1}$ ofloxacin solution. The general analytical procedure was then followed.

The pharmaceutical preparations had the following composition per tablets: Chemidarou (Iran), $200 \mathrm{mg}$; Exir (Iran), 200 mg; and Rouz Daru (Iran), 300 mg of ofloxacin. Five tablets of each pharmaceutical formulation were weighed individually to an average weight. The tablets were finely powdered and mixed, and a mass corresponding to one tablet for each formulation was weighed and dissolved in sodium hydroxide, followed by dilution with double distilled deionized water in $100 \mathrm{~mL}$ volumetric flask. Serial dilutions were performed and the analysis was then followed in the general analytical procedure.
Calculation of enrichment factor (EF) and preconcentration factor (PF)

Enrichment factor (EF) is the ratio of the analyte concentration in the settled phase to the initial analyte concentration $\left(\mathrm{C}_{0}\right)$ in the aqueous sample.

$\mathrm{EF}=\mathrm{C}_{\mathrm{set}} / \mathrm{C}_{0}$

The preconcentration factor (PF) is calculated as the ratio of the initial sample volume $\left(\mathrm{V}_{\mathrm{aq}}\right)$ and the settled phase volume $\left(\mathrm{V}_{\text {set }}\right)$.

$\mathrm{PF}=\mathrm{V}_{\mathrm{aq}} / \mathrm{V}_{\text {set }}$

Here, $\mathrm{V}_{\mathrm{aq}}$ and $\mathrm{V}_{\text {set }}$ are the aqueous sample and sediment phase volumes, respectively.

Type and volume of extraction and dispersive solvents

Extraction solvent, which should have a higher density than water and low miscibility with sample in order to obtain proper selectivity with high efficiency, is an important parameter in the DLLME process. ${ }^{46}$ Therefore, carbon tetrachloride, dichloromethane, chloroform, and nitrobenzene were examined as extraction solvents for ofloxacin. Chloroform had the highest enrichment factor and yielded the most stable cloudy solutions, according to the results obtained.

The dispersive solvent in DLLME should be miscible with the organic and aqueous phases and should be able to disperse the extraction solvent into tiny drops in the aqueous phase. Acetone, acetonitrile, ethanol, and methanol were tested as dispersive solvents in this regard. Acetonitrile gave the best recovery among the solvents tested. Samples of $550 \mu \mathrm{L}$ from these extraction solvents were mixed with $225 \mu \mathrm{L}$ of dispersive solvents and examined to select the appropriate extraction and dispersive solvents.

\section{Effect of $\mathrm{pH}$}

An important factor in the liquid-liquid extraction process is the solution $\mathrm{pH}$. The ionic form of a neutral molecule, resulting from protonation or proton donation in acidic or alkaline media, cannot be extracted from the aqueous phase into the organic phase. Therefore, in microextraction, the $\mathrm{pH}$ should be adjusted in order to extract the analyte as a neutral molecule. The effect of $\mathrm{pH}$ was studied in the range of 3-8; the optimal $\mathrm{pH}$ was found to be 4.5 . 


\section{Effect of salt}

The effect of ionic strength was evaluated by adding $0-3 \%(\mathrm{~m} / \mathrm{v}) \mathrm{NaCl}$ under constant conditions. The extraction efficiency was shown to increase by adding salt, due to the reduction of analyte solubility in water. The results obtained are discussed in the Results and Discussion section.

\section{Effect of extraction time}

The interval between the injection of solvent mixture and the centrifugation is called extraction time in the DLLME process. In order to study the effect of extraction time, it was kept in the range of 0-30 min. The results indicated that extraction efficiency is not affected by extraction time. In fact, an interface is developed between the extraction and the aqueous phase after the formation of the cloudy solution, which enhances the extraction of the analyte from the aqueous phase into the extraction phase, resulting in a quick equilibrium state. One of the most significant benefits of this method is the short extraction time.

\section{Results and Discussion}

Several parameters, such as extraction and dispersive solvent type and volume, solution $\mathrm{pH}$, aqueous phase ionic strength, and extraction time, influence the ofloxacin enrichment factor in the DLLME process. These variables were optimized through the one-variable-at-a-time (OVAT) process. The OVAT design is a classical univariate method consisting of the investigation of the response for each factor, while all other factors are held constant. BBD was then used to optimize the effective levels of variables in the extraction of the ofloxacin and RSM was applied to analyze the effect of the independent factors on the response, in order to evaluate the relative significance of several affecting factors.

\section{Box-Behnken design}

According to the $\mathrm{BBD}$ method, ${ }^{47}$ the extraction solvent volume $\left(\mathrm{X}_{1}\right)$, dispersive solvent volume $\left(\mathrm{X}_{2}\right)$, solution $\mathrm{pH}\left(\mathrm{X}_{3}\right)$, and ionic strength $\left(\mathrm{X}_{4}\right)$ influence the response of OVAT experiments. These were studied as variables for assigning their optimal levels and designing a model. The number of experiments $(\mathrm{N})$ required to develop the design is defined as equation 3 :

$\mathrm{N}=2 \mathrm{k}(\mathrm{k}-1)+\mathrm{C}_{0}$

Here, $\mathrm{k}$ is the factor number and $\mathrm{C}_{0}$ is the central point ${ }^{48}$ replicate number. Thus, a total of 27 runs, including three central points, were carried out to study the effect of four variables at three different levels (low, medium, and high). The design central point was replicated three times to estimate the error. The optimization of the critical factors and definition of the nature of response surface in the experiments were performed using RSM. Table 1 shows a list of factors, the corresponding symbols, and levels. The experimental design matrices and the values of responses under different experimental combinations are presented in Table 2.

Table 1. Level of variables used in BBD (Box-Behnken design) for OFL (ofloxacin) extraction

\begin{tabular}{lccc}
\hline \multirow{2}{*}{ Factor } & \multicolumn{3}{c}{ Levels } \\
\cline { 2 - 4 } & Low (-1) & Medium (0) & High (+1) \\
\hline $\begin{array}{l}\left.\mathrm{X}_{1}\right) \text { Volume of extraction } \\
\text { solvent / } \mu \mathrm{L}\end{array}$ & 200 & 225 & 250 \\
$\begin{array}{l}\left.\mathrm{X}_{2}\right) \text { Volume of disperser } \\
\text { solvent / } \mu \mathrm{L}\end{array}$ & 500 & 550 & 600 \\
$\left(\mathrm{X}_{3}\right) \mathrm{pH}$ of sample solution & 3 & 4.5 & 6 \\
$\left(\mathrm{X}_{4}\right)$ Ionic strength & 0.0 & 1.5 & 3 \\
$(\mathrm{NaCl}$ concentration, $\mathrm{m} / \mathrm{v}) / \%$ & & & \\
\hline
\end{tabular}

The equation correlating the independent variables and the response is defined as a second-order polynomial model (equation 4):

$Y=\beta_{0}+\beta_{1} X_{1}+\beta_{2} X_{2}+\beta_{3} X_{3}+\beta_{4} X_{4}+\beta_{12} X_{1} X_{2}+$ $\beta_{13} X_{1} X_{3}+\beta_{14} X_{1} X_{4}+\beta_{23} X_{2} X_{3}+\beta_{24} X_{2} X_{4}+\beta_{34} X_{3} X_{4}+$ $\beta_{11} X_{1}^{2}+\beta_{22} X_{2}^{2}+\beta_{33} X_{3}^{2}+\beta_{44} X_{4}^{2}$

Here, $\mathrm{Y}$ is the predicted response; $\beta_{0}$ is the intercept coefficient; $\beta_{1}, \beta_{2}, \beta_{3}$, and $\beta_{4}$ are linear coefficients; $\beta_{12}$, $\beta_{13}, \beta_{14}, \beta_{23}, \beta_{24}$, and $\beta_{34}$ are cross product coefficients; $\beta_{11}$, $\beta_{22}, \beta_{33}$, and $\beta_{44}$ are the quadratic coefficients, and $X_{\mathrm{i}}$ values are independent variables. RSM was then applied to define the empirical relationship between $\mathrm{Y}$ and the variables. Equation 5 shows the response functions $(\mathrm{Y})$ with the determined coefficients:

$Y=-205.94+10.66 X_{1}+2.27 X_{2}+118.98 X_{3}+$
$45.68 X_{4}-0.01 X_{1} X_{3}-0.05 X_{1} X_{4}-0.03 X_{2} X_{3}-$
$0.02 X_{2} X_{4}-4.95 X_{3} X_{4}-0.02 X_{1}^{2}-10.63 X_{3}^{2}+0.48 X_{4}^{2}(5)$

The optimal set for the maximum percentage of $\mathrm{Y}$ was obtained as follows: $X_{1}=600, X_{2}=225, X_{3}=4.1, X_{4}=3$.

\section{Statistical analysis}

The statistical significance of the model was evaluated using the analysis of variance (ANOVA). The results are 
Table 2. Design matrix and obtained result for Box-Behnken design (BBD)

\begin{tabular}{|c|c|c|c|c|c|}
\hline \multirow{2}{*}{ Run } & \multicolumn{4}{|c|}{ Coded level of factors } & \multirow[t]{2}{*}{$\mathrm{R} \%$} \\
\hline & $X_{1}$ & $\mathrm{X}_{2}$ & $\mathrm{X}_{3}$ & $\mathrm{X}_{4}$ & \\
\hline 1 & -1 & -1 & 0 & 0 & 70.01 \\
\hline 2 & 1 & -1 & 0 & 0 & 67.04 \\
\hline 3 & -1 & 1 & 0 & 0 & 81.90 \\
\hline 4 & 1 & 1 & 0 & 0 & 72.01 \\
\hline 5 & 0 & 0 & -1 & -1 & 57.50 \\
\hline 6 & 0 & 0 & 1 & -1 & 70.11 \\
\hline 7 & 0 & 0 & -1 & 1 & 86.96 \\
\hline 8 & 0 & 0 & 1 & 1 & 55.02 \\
\hline 9 & -1 & 0 & 0 & -1 & 72.03 \\
\hline 10 & 1 & 0 & 0 & -1 & 78.01 \\
\hline 11 & -1 & 0 & 0 & 1 & 80.03 \\
\hline 12 & 1 & 0 & 0 & 1 & 79.10 \\
\hline 13 & 0 & -1 & -1 & 0 & 57.06 \\
\hline 14 & 0 & 1 & -1 & 0 & 66.58 \\
\hline 15 & 0 & -1 & 1 & 0 & 61.02 \\
\hline 16 & 0 & 1 & 1 & 0 & 63.01 \\
\hline 17 & -1 & 0 & -1 & 0 & 56.11 \\
\hline 18 & 1 & 0 & -1 & 0 & 60.07 \\
\hline 19 & -1 & 0 & 1 & 0 & 56.10 \\
\hline 20 & 1 & 0 & 1 & 0 & 58.12 \\
\hline 21 & 0 & -1 & 0 & -1 & 82.04 \\
\hline 22 & 0 & 1 & 0 & -1 & 94.05 \\
\hline 23 & 0 & -1 & 0 & 1 & 93.61 \\
\hline 24 & 0 & 1 & 0 & 1 & 98.99 \\
\hline 25 & 0 & 0 & 0 & 0 & 91.97 \\
\hline 26 & 0 & 0 & 0 & 0 & 95.06 \\
\hline 27 & 0 & 0 & 0 & 0 & 87.91 \\
\hline
\end{tabular}

$\mathrm{R} \%$ : recovery percentage.

presented in the Table 3. If $p$-value, the smallest level of significance, is below 0.05 , the model is statistically definable. The determination coefficient $\left(\mathrm{R}^{2}\right)$ was $94.46 \%$, which was used in the evaluation of the model aptitude. The $\mathrm{R}^{2}$ value also indicates strong agreement between the experimental and predicted responses. The failure of the model to represent the experimental data in the experimental domain at the points not included in the regression analysis is measured by the lack-of-fit test. ${ }^{49}$ The lack-of-fit (0.361) was not significant ( $p$-value $>0.05$ ).

\section{Interaction effects of extraction variables}

The effect of different variables on the response factor is visualized by the three-dimensional response surface plots (Figures 2a-2f). The cross-effects of the variables
Table 3. Analysis of variance (ANOVA) for Box-Behnken design (BBD)

\begin{tabular}{|c|c|c|c|c|c|}
\hline Variable & $\begin{array}{l}\text { Sum of } \\
\text { square }\end{array}$ & $\begin{array}{l}\text { Degree of } \\
\text { freedom }\end{array}$ & $\begin{array}{l}\text { Mean } \\
\text { square }\end{array}$ & $F$-Value & $p$-Value \\
\hline $\mathrm{X}_{1}$ & 0.33 & 1 & 758.63 & 31.66 & 0.000 \\
\hline $\mathrm{X}_{2}$ & 175.41 & 1 & 113.06 & 4.72 & 0.051 \\
\hline $\mathrm{X}_{3}$ & 36.15 & 1 & 553.16 & 23.08 & 0.000 \\
\hline $\mathrm{X}_{4}$ & 133.00 & 1 & 87.60 & 3.66 & 0.080 \\
\hline $\mathrm{X}_{1}^{2}$ & 450.12 & 1 & 982.55 & 41.00 & 0.000 \\
\hline $\mathrm{X}_{2}^{2}$ & 20.11 & 1 & 82.72 & 3.45 & 0.088 \\
\hline $\mathrm{X}_{3}^{2}$ & 3535.43 & 1 & 3050.62 & 127.31 & 0.000 \\
\hline $\mathrm{X}_{4}^{2}$ & 6.15 & 1 & 6.15 & 0.26 & 0.622 \\
\hline $\mathrm{X}_{1} \mathrm{X}_{2}$ & 11.90 & 1 & 11.90 & 0.50 & 0.494 \\
\hline $\mathrm{X}_{1} \mathrm{X}_{3}$ & 1.10 & 1 & 1.10 & 0.05 & 0.834 \\
\hline $\mathrm{X}_{1} \mathrm{X}_{4}$ & 12.25 & 1 & 12.25 & 0.51 & 0.488 \\
\hline $\mathrm{X}_{2} \mathrm{X}_{3}$ & 14.36 & 1 & 14.36 & 0.60 & 0.454 \\
\hline $\mathrm{X}_{2} \mathrm{X}_{4}$ & 10.89 & 1 & 10.89 & 0.45 & 0.513 \\
\hline $\mathrm{X}_{3} \mathrm{X}_{4}$ & 496.73 & 1 & 496.73 & 20.73 & 0.001 \\
\hline Residual error & 287.55 & 12 & 23.96 & & \\
\hline Lack-of-fit & 262.88 & 10 & 26.29 & 2.13 & 0.361 \\
\hline Pure error & 24.67 & 2 & 12.33 & & \\
\hline
\end{tabular}

cause the bending of these plots. According to the response surface plot of Figure 2a, the recovery percentage (R\%) is reduced with the reduction in the acetonitrile and chloroform volume, which is possibly due to the inability of the extraction solvent to disperse properly and the lack of a proper cloudy solution. An increase in the acetonitrile volume increases the recovery percentage in a medium amount of chloroform, until it finally reaches a plateau state. A high volume of acetonitrile has a negative effect on $\mathrm{R} \%$ when a high volume of chloroform $(240-250 \mu \mathrm{L})$ is used, based on the results. This may be due to an increased solubility of the analyte on increasing the amount of dispersive solvent. The optimal R\% is about 94 when $570-600 \mu \mathrm{L}$ of acetonitrile and $200-225 \mu \mathrm{L}$ of chloroform are used as disperser and extraction solvents, respectively.

$\mathrm{R} \%$ decreases with a decrease in $\mathrm{pH}$ and extraction solvent (ca. 35\%), as shown in Figure 2b. In addition, $\mathrm{R} \%$ rises to $88 \%$ when the extraction solvent $\mathrm{pH}$ and volume reach 4.5 and $225 \mu \mathrm{L}$, respectively. As observed in Figure 2c, the extraction efficiency increases in the region where the acetonitrile volume and $\mathrm{pH}$ are set at $600 \mu \mathrm{L}$ and 4.5 , respectively. High R\% of about $94 \%$ is observed in the region when the amount of $\mathrm{NaCl}$ is the lowest and $\mathrm{pH}$ is 4.5 (Figure 2d). The best level of extraction efficiency is observed when the amount of $\mathrm{NaCl}$ is the highest and the chloroform and acetonitrile volumes are about 225 and $570 \mu \mathrm{L}$, respectively (Figures 2e and 2f). 
(a)

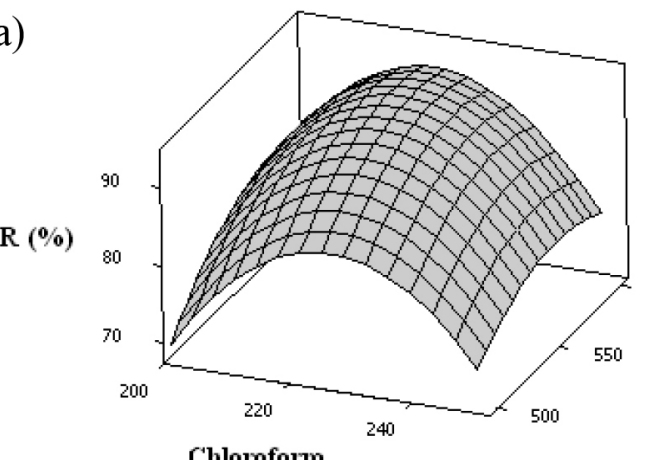

Chloroform

(c)

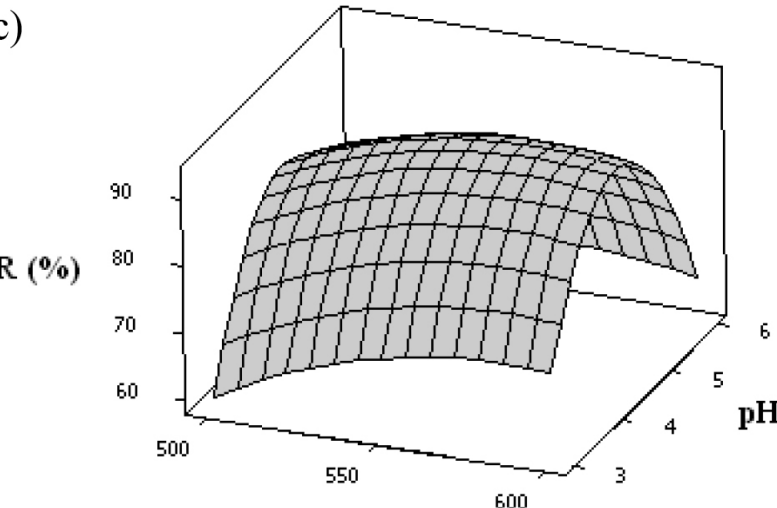

Acetonitrile (b)

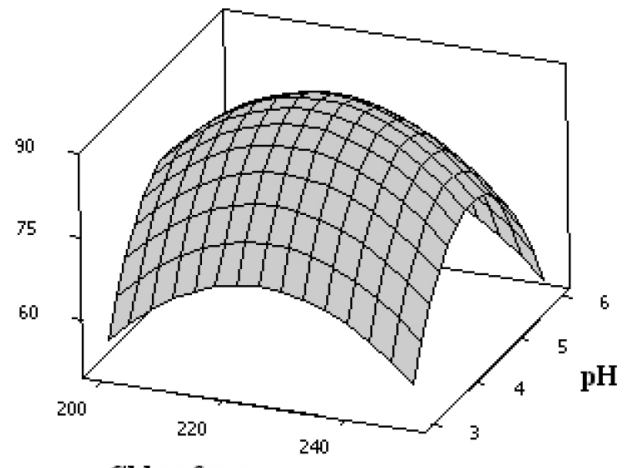

Chloroform

(d)

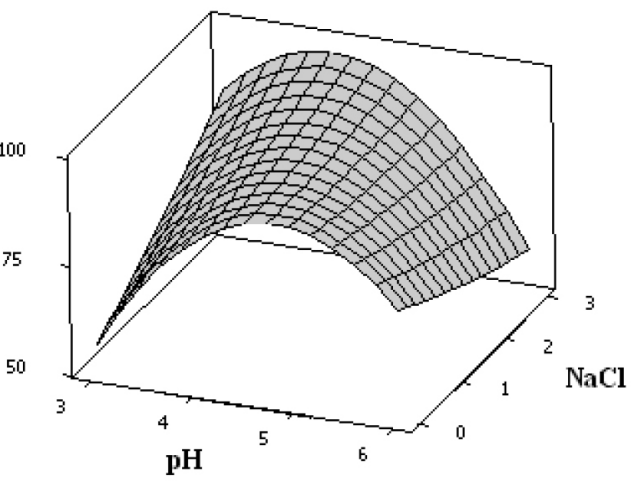

(e)

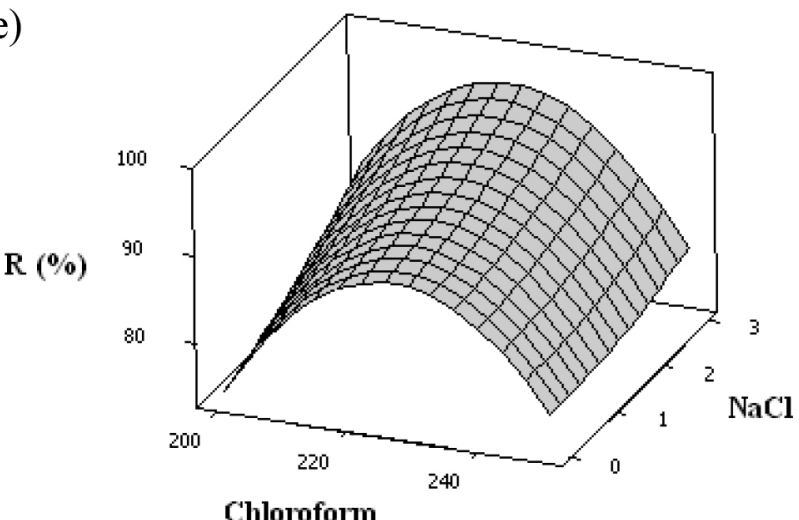

(f)

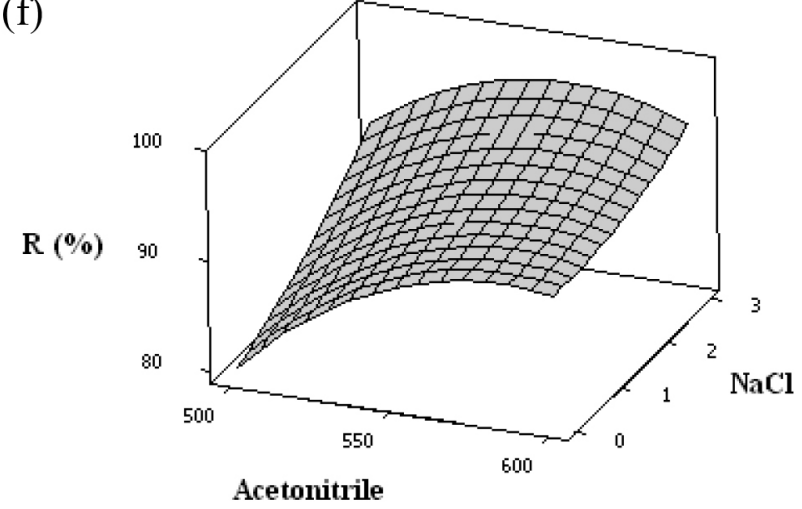

Figure 2. Response surface plots for the BBD: (a) $\mathrm{X}_{1}-\mathrm{X}_{2}$; (b) $\mathrm{X}_{1}-\mathrm{X}_{3}$; (c) $\mathrm{X}_{2}-\mathrm{X}_{3}$; (d) $\mathrm{X}_{3}-\mathrm{X}_{4}$; (e) $\mathrm{X}_{1}-\mathrm{X}_{4}$; (f) $\mathrm{X}_{2}-\mathrm{X}_{4}$.

Analytical parameters of DLLME

Analytical parameters of the proposed method are considered under the optimal conditions. The results are shown in Table 4. Under the optimal conditions, a calibration curve was obtained with a linear dynamic range for eight prepared ofloxacin solution samples with concentrations in 5.0-120.0 $\mathrm{ng} \mathrm{mL}^{-1}$ range and a correlation coefficient $\mathrm{R}^{2}$ of 0.9948 . The relative standard deviation (RSD) for seven replicate measurements using $10 \mathrm{ng} \mathrm{mL}^{-1}$ ofloxacin was $1.13 \%$. The enrichment factor, i.e. the slope of the calibration curve after extraction divided by that before extraction, was found to be 51 based on the slope of the calibration line. Standard deviation of the blank solution $\left(\mathrm{S}_{\mathrm{b}}\right)$ was estimated using the residual $\left(\mathrm{S}_{\mathrm{y} / \mathrm{x}}\right)$ with a linear dynamic range of $5.0-120.0 \mathrm{ng} \mathrm{mL}^{-1}$. The limit of detection (LOD), defined as $3 \mathrm{~S}_{\mathrm{b}} /$ slope, was $1.61 \mathrm{ng} \mathrm{mL}^{-1}$.

There are no reports for OFL determination in urine sample using the method we have proposed in this study. The results obtained in the present work and those reported 
Table 4. Analytical characteristics of DLLME (dispersive liquid-liquid microextraction) for the determination of ofloxacin

\begin{tabular}{lc}
\hline Parameter & Analytical feature \\
\hline Dynamic range $/\left(\mathrm{ng} \mathrm{mL}^{-1}\right)$ & $5.0-120.0$ \\
Calibration equation before & $\mathrm{y}=0.043 \mathrm{x}+0.21207\left(\mathrm{R}^{2}=0.9918\right)$ \\
microextraction & \\
Calibration equation after & $\mathrm{y}=2.1846 \mathrm{x}+0.11634$ \\
microextraction & $\left(\mathrm{R}^{2}=0.9967\right)$ \\
Repeatability $(\mathrm{RSD} / \%)(\mathrm{n}=7)$ & 1.13 \\
Limit of detection / $\left(\mathrm{ng} \mathrm{mL} \mathrm{mL}^{-1}\right)$ & 1.61 \\
Enrichment factor & 51 \\
Preconcentration factor & $>50$ \\
\hline
\end{tabular}

$\mathrm{R}^{2}$ : determination coefficient; RSD: relative standard deviation.

by other researchers using different methods for the determination of ofloxacin are compared in Table 5. The analytical parameters are obviously comparable or better than the results reported for ofloxacin determination.

\section{PLS analysis}

Multivariate calibration is a powerful measurement tool, since it can extract more information from data and the models can be built more effectively. PLS modeling is a multivariate statistical tool that is performed using easily accessible statistical software. Thus, a PLS model was prepared and registered for an excitation wavelength in the 200-350 $\mathrm{nm}$ range for each $10 \mathrm{~nm}$, while emission wavelength was in the range of $400-650 \mathrm{~nm}$ for every $\mathrm{nm}$.

A training set, including 15 samples as a calibration set and five samples not included in the previous set, were prepared for a validation set. The model was validated by cross-validation (leave-one-out) for defining the principal component number. OSC, a pre-processing technique eliminating the unrelated parts of target information based on the constrained PCA, is an appropriate method for the pre-processing of PLS calibration without a loss in prediction capacity, using the spectrophotometric method used for filtering calibration set.

RMSEP and RSEP values were used as parameters for the comparison of the models. Table 6 shows the results obtained for each of the above approaches. The prediction error sum of squares (PRESS) for cross-validated models was calculated to determine the optimal number of factors (latent variables) to be included in the PLS calibration model. A reasonable choice for the optimal number of factors is the one yielding the minimum PRESS. In many cases, the minimum PRESS value causes overfitting for unknown samples that are not included in the model, because there are a finite number of samples in the training set. Haaland and Thomas ${ }^{52}$ have suggested a solution to this problem, in which the PRESS values for all the previous factors are compared to that at the minimum. The significance of PRESS values greater than the minimum value is determined using the $F$-statistical test.

Table 6 summarizes the optimal number of factors and PRESS values for ofloxacin. The optimal number of factors (N.F.) of PLS for ofloxacin (N.F. $=4$, PRESS = 3.3677) is larger than the theoretically expected value of 1 . Thus, OSC pre-processing is carried out to decrease the number of factors (N.F. $=2$ and PRESS $=0.4423$ ) and shift to theoretical values. Table 6 shows the LOD ${ }^{53}$ of ofloxacin determination using PLS and OSC-PLS methods. LOD is completely acceptable for the OSC-PLS method, as observed. In fact, the OSC method removes the information from the spectrofluorimetric data that is not necessary for fitting the concentration variables, as implied by the results.

\section{Parallel factor analysis (PARAFAC)}

As a three-dimensional multivariate calibration, the major benefit of PARAFAC is the concentration of the information of an individual component that is allowed to be extracted in the presence of any number of uncalibrated constituents. ${ }^{54}$ To prepare the PARAFAC model, two such matrices were first formed: one with the application of OSC to each set of data to filter the calibration set and one without OSC pre-processing. The data was then arranged in a $16 \times 15 \times 251$ three-dimensional array consisting of 15 solutions with different ofloxacin concentrations in the rows (5.0-120.0 $\left.\mathrm{ng} \mathrm{mL}^{-1}\right), 251$ emission wavelengths in

Table 5. Comparison of the proposed method with similar reports for determination of ofloxacin

\begin{tabular}{lcccccc}
\hline Method & Detection system & $\mathrm{LDR}^{\mathrm{a}} /\left(\mathrm{ng} \mathrm{mL}^{-1}\right)$ & $\mathrm{EF}^{\mathrm{b}}, \mathrm{PF}^{\mathrm{c}}$ & $\mathrm{LOD}^{\mathrm{d}} /\left(\mathrm{ng} \mathrm{mL}^{-1}\right)$ & $\mathrm{RSD}^{\mathrm{e}} / \%$ & $\mathrm{Reference}^{\circ}$ \\
\hline M-IL-CIA-DLLME $^{\mathrm{f}}$ & spectrofluorimeter & $0.15-125.0$ & $50^{\mathrm{c}}$ & 0.029 & 2.7 & 3 \\
EA-SS-LPME $^{\mathrm{g}}$ & HPLC-FLD & $0.01-1.08$ & - & 3.97 & 4 & 50 \\
UA-DLLME $^{\mathrm{h}}$ & LC-UV & $10.0-200.0$ & - & $0.14-0.81$ & 5.2 & 51 \\
DLLME & spectrofluorimeter & $5.0-120.0$ & $51^{\mathrm{b}}$ & 1.13 & 1.61 & current work \\
\hline
\end{tabular}

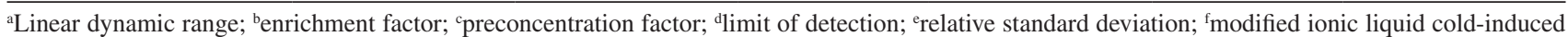
aggregation dispersive liquid-liquid microextraction; ${ }^{\mathrm{g}}$ effervescence-assisted switch-able solvent-based liquid phase microextraction; ${ }^{\mathrm{h}}$ ultrasound-assisted dispersive liquid-liquid microextraction; 'i high-performance liquid chromatography-fluorescence detection. 
Table 6. Added and obtained results of the prediction set of ofloxacin using different methods

\begin{tabular}{|c|c|c|c|c|c|}
\hline \multirow{3}{*}{ Added OFL / $\left(\mathrm{ng} \mathrm{mL} \mathrm{m}^{-1}\right)$} & \multicolumn{5}{|c|}{ Obtained OFL / $\left(\mathrm{ng} \mathrm{mL}^{-1}\right)$} \\
\hline & \multirow{2}{*}{$\begin{array}{c}\text { Univariate calibration } \\
\text { Classic }\end{array}$} & \multicolumn{4}{|c|}{ Multivariate calibration } \\
\hline & & PLS & OSC-PLS & PARAFAC & OSC-PARAFAC \\
\hline 25.0 & 19.9 & 25.8 & 26.2 & 24.6 & 25.6 \\
\hline 65.0 & 59.5 & 63.5 & 64.0 & 66.1 & 64.1 \\
\hline 75.0 & 70.2 & 74.2 & 74.5 & 74.0 & 74.8 \\
\hline 85.0 & 83.1 & 84.1 & 84.4 & 85.1 & 84.6 \\
\hline 95.0 & 89.1 & 94.6 & 94.8 & 94.3 & 95.4 \\
\hline Number of factor & - & 4 & 2 & 2 & 1 \\
\hline RMSEP & 4.88 & 0.94 & 0.82 & 0.51 & 0.31 \\
\hline RSEP & 6.68 & 1.29 & 1.12 & 0.69 & 0.42 \\
\hline PRESS & - & 4.42 & 3.37 & - & - \\
\hline $\mathrm{LOD} /\left(\mathrm{ng} \mathrm{mL} \mathrm{m}^{-1}\right)$ & 1.6 & 1.2 & 0.7 & 1.0 & 0.6 \\
\hline$\gamma /\left(\mathrm{ng} \mathrm{mL}^{-1}\right)$ & 98.6 & 63.2 & 35.3 & 55.5 & 23.1 \\
\hline
\end{tabular}

OFL: ofloxacin; RMSEP: root mean squares error of prediction; RSEP: relative standard error of prediction; PRESS: prediction error sum of squares; LOD: limit of detection; $\gamma$ : analytical sensitivity; PLS: partial least squares; OSC-PLS: orthogonal signal correction partial least square; PARAFAC: parallel factor analysis; OSC-PARAFAC: orthogonal signal correction parallel factor analysis.

the columns (400-650 $\mathrm{nm}$ for every $\mathrm{nm}$ ), and 16 excitation wavelengths in the slices (200-350 nm for every $10 \mathrm{~nm}$ ). For each data matrix, the calibration curves were obtained by plotting the loading vs. real concentrations of ofloxacin. Table 7 gives the statistical parameters of the linear regression of the calibration equations.

Table 7. Statistical parameters of the linear relationship between the proportion loadings calculated by PARAFAC and OSC-PARAFAC

\begin{tabular}{lcc}
\hline & PARAFAC & OSC-PARAFAC \\
\hline Number of data point & 15 & 15 \\
Intercept & 0.0412 & 0.0242 \\
Standard deviation of intercept & 0.7684 & 0.2332 \\
Slope & 0.0033 & 0.0041 \\
Standard deviation of slope & 0.0112 & 0.0035 \\
Correlation coefficient & 0.9812 & 0.9843
\end{tabular}

PARAFAC: parallel factor analysis; OSC-PARAFAC: orthogonal signal correction parallel factor analysis.

The method accuracy was evaluated through RMSEP and RSEP. The RMSEP and RSEP values were also applied for the validation of the model for the prediction of the validation set. The results of the prediction for ofloxacin were completely acceptable for the OSC-PARAFAC method. The results obtained by applying PARAFAC to five synthetic samples are listed in Table 6.

\section{Figures of merit}

Analytical sensitivity $(\gamma)$ and LOD can be calculated with NAS (net analyte signal) method and used for the proposed method performance. Analytical sensitivity can be expressed as: $\gamma=\mathrm{SEN} /\|\mathrm{S} *\|$. Here, SEN is the sensitivity that estimated as the net analyte signal and $\left\|S^{*}\right\|$ is the pure spectrum norm of the $\mathrm{i}$ analyte of interest.

Also, the equation LOD $=3\|\varepsilon\|\|\mathrm{S}\|$ has been proposed for estimating the LOD, here $\|\varepsilon\|$ is a measure of the instrumental noise and $\|S\|$ is the total spectrum norm of the test samples. The value of $\|\varepsilon\|$ may be estimated, in turn, by registering the spectra for several blank samples, calculating the norm of the NAS for each sample, and the corresponding standard deviation..$^{55,56}$

\section{Determination of ofloxacin in real samples}

Several spiked urine and serum samples were used to determine the predictive capacity of the proposed methods. Table 8 shows the results obtained by applying the OSC-PLS and OSC-PARAFAC algorithms to eight and four validation samples for urine and serum, respectively. The satisfactory recovery of ofloxacin can be achieved using the recommended procedures, according to the results. Moreover, the OSC-PARAFAC method is clearly superior to OSC-PLS in terms of the determination of ofloxacin in complex matrices, such as human urine, without considerable error. Therefore, the OSC-PARAFAC model is desirable for predicting the concentrations of OFL in real matrix samples. Table 8 summarizes the recoveries in complex matrices (human urine and serum). In order to show the analytical applicability of the proposed method, it was applied to determinate ofloxacin in commercial tablets. The results showed that satisfactory recovery for ofloxacin could be obtained using the recommended procedures. The data obtained by the methods reveal the capability of the 
Table 8. Determination of ofloxacin in real samples by DLLME using OSC-PLS and OSC-PARAFAC

\begin{tabular}{|c|c|c|c|c|c|}
\hline \multirow{2}{*}{ Sample } & \multirow{2}{*}{ Added OFL } & \multicolumn{4}{|c|}{ Obtained OFL / $\left(\mathrm{ng} \mathrm{mL}^{-1}\right)$} \\
\hline & & OSC-PLS & Recovery / \% & OSC-PARAFAC & Recovery / \% \\
\hline Urine sample 1 & 26.0 & $23.0 \pm 0.2$ & 88.5 & $25.0 \pm 0.2$ & 96.2 \\
\hline Urine sample 2 & 45.0 & $41.4 \pm 0.4$ & 92.0 & $43.7 \pm 0.4$ & 97.1 \\
\hline Urine sample 3 & 54.0 & $56.1 \pm 0.4$ & 103.9 & $55.4 \pm 0.4$ & 102.6 \\
\hline Urine sample 4 & 67.0 & $62.7 \pm 0.6$ & 93.6 & $64.2 \pm 0.6$ & 95.8 \\
\hline Urine sample 5 & 86.0 & $89.0 \pm 0.7$ & 103.5 & $88.0 \pm 0.7$ & 102.3 \\
\hline Urine sample 6 & 96.0 & $101.0 \pm 1.3$ & 105.2 & $98.6 \pm 0.9$ & 102.7 \\
\hline Urine sample 7 & 106.0 & $98.3 \pm 1.1$ & 92.7 & $101.3 \pm 1.1$ & 95.5 \\
\hline Urine sample 8 & 116.0 & $110.0 \pm 1.5$ & 94.8 & $111.9 \pm 1.4$ & 96.5 \\
\hline Serum sample 1 & 7.0 & $6.2 \pm 0.1$ & 88.3 & $6.59 \pm 0.1$ & 94.1 \\
\hline Serum sample 2 & 30.0 & $25.3 \pm 0.3$ & 84.3 & $27.5 \pm 0.3$ & 91.7 \\
\hline Serum sample 3 & 55.0 & $58.4 \pm 0.4$ & 106.2 & $56.9 \pm 0.4$ & 103.4 \\
\hline Serum sample 4 & 92.0 & $85.1 \pm 0.6$ & 92.5 & $88.2 \pm 0.6$ & 95.9 \\
\hline
\end{tabular}

OFL: ofloxacin; OSC-PLS: orthogonal signal correction partial least square; OSC-PARAFAC: orthogonal signal correction parallel factor analysis.

Table 9. Determination of ofloxacin in pharmaceutical preparations using the OSC-PLS and OSC-PARAFAC models

\begin{tabular}{lccccc}
\hline $\begin{array}{l}\text { Pharmaceutical } \\
\text { preparations }\end{array}$ & $\left.\begin{array}{c}\text { Label claim } / \\
(\mathrm{mg} \text { tablet }\end{array}\right)$ & OSC-PLS & Recovery / \% & OSC-PARAFAC & Recovery / \% \\
\cline { 3 - 6 } Chemidarou $^{\mathrm{a}}$ & 200.0 & $190.1 \pm 1.8$ & 95.1 & $191.5 \pm 1.7$ & 95.8 \\
Exir $^{\mathrm{b}}$ & 200 & $204.3 \pm 1.9$ & 102.2 & $202.7 \pm 1.9$ & 101.4 \\
Rouz Darou $^{\mathrm{c}}$ & 300.0 & $286.8 \pm 2.6$ & 95.6 & $290.6 \pm 2.4$ & 96.8 \\
\hline
\end{tabular}

a Tablet (from Chemidarou Ltd., Iran); btablet (from Exir Ltd., Iran); 'tablet (from Rouz Darou Ltd., Iran). OSC-PLS: orthogonal signal correction partial least square; OSC-PARAFAC: orthogonal signal correction parallel factor analysis.

methods for determination of ofloxacin in pharmaceutical formulations without considerable error. The results of the recovery from pharmaceutical formulations (Chemidarou, Exir and Rouz Darou tablets) are given in Table 9.

\section{Conclusions}

DLLME has been coupled with spectrofluorimetry for the extraction and determination of ofloxacin in several different samples such as biological (human urine and serum) and pharmaceutical formulations samples in this work. There are many benefits of this method, such as operation simplicity, low cost, rapidity of the process, low toxicity, high efficiency, and less consumption of organic solvents. This method is also highly sensitive, selective, and well-repeatable with a good LOD. The impacts of different variables were considered in this research. BBD involving RSM was used in the determination of the optimal operating conditions, yielding the maximum recovery percent $(\mathrm{R} \%)$ and the evaluation of the effect of factors and the interactions among them on the extraction efficiency.

PLS and PARAFAC multivariate calibration models, with and without OSC pre-processing, were used for fluorescence spectra deconvolution and ofloxacin quantification and the results were statistically comparable. The capacity of the method for the analysis of pharmaceutical preparations and real samples was also evaluated through the satisfactory determination of ofloxacin in the samples. In conclusion, the model developed by the OSC-PARAFAC method has more predictive ability, especially for real samples compared with OSC-PLS method, which undoubtedly shows that the tolerance limit of three-way calibration methods for the matrix effect is higher than that of the two-way methods.

\section{Acknowledgments}

The authors gratefully acknowledge the support of this work by the Islamic Azad University, Arak Branch.

\section{References}

1. Nelson, J. M.; Chiller, T. M.; Powers, J. H.; Angulo, F. J.; Clin. Infect. Dis. 2007, 44, 977.

2. Ichihara, N.; Tachizawa, H.; Tsumura, M.; Une, T.; Sato, K.; Chemotherapy 1984, 32, 118. 
2300 Application of Response Surface Modeling and Chemometrics Methods for the Determination of Ofloxacin in Human Urine J. Braz. Chem. Soc.

3. Zeeb, M.; Ganjali, M. R.; Norouzi, P.; DARU 2011, 19, 446.

4. Schönfeld, W.; Knöller, J.; Bremm, K. D.; Dahlhoff, A.; Weber, B.; König, W.; Zentralbl. Bakteriol., Mikrobiol. Hyg., Ser. A 1986, 261, 338 .

5. Mizuno, A.; Uematsu, T.; Nakashima, M.; J. Chromatogr. B: Biomed. Sci. Appl. 1994, 653, 187.

6. Vallée, F.; LeBel, M.; Bergeron, M. G.; Ther. Drug Monit. 1986, 8,340 .

7. Vinay, K. B.; Revanasiddappa, H. D.; Divya, M. R.; Rajendraprasad, N.; Ecletica Quim. 2009, 34, 65.

8. Vinay, K. B.; Revanasiddappa, H. D.; Devi, O. Z.; Ramesh, P. J.; Basavaiah, K.; Braz. J. Pharm. Sci. 2011, 47, 251.

9. Pulgarín, J. A.; Molina, A. A.; Boras, N.; Appl. Spectrosc. 2013, 67, 1029.

10. Tong, Z.; Bianfei, Y.; Wanjin, T.; Haixia, Z.; Spectrochim. Acta, Part A 2015, 148, 125.

11. Wang, P.; Zhou, M.; Feng, Y.; Chen, L.; Anal. Lett. 1998, 31, 1523.

12. Feng, Y. L.; Dong, C.; J. Chromatogr. Sci. 2004, 42, 474.

13. Liu, Y. M.; Shi, Y. M.; Liu, Z. L.; Biomed. Chromatogr. 2010 , 24, 941.

14. See, K. L.; Elbashir, A.; Saad, B.; Aboul-Enein, H. Y.; Biomed. Chromatogr. 2009, 23, 1283.

15. Chen, L.; Wang, X.; Zhao, H.; Wang, K.; Jin, L.; Luminescence 2008, 23, 309

16. Sun, H.; Li, L.; Chen, X.; Anal. Sci. 2006, 22, 1145.

17. Rezaee, M.; Assadi, Y.; Milani Hosseini, M. R.; Aghaee, E.; Ahmadi, F.; Berijani, S.; J. Chromatogr. A 2006, 1116, 1.

18. Rezaee, M.; Yamini, Y.; Faraji, M.; J. Chromatogr. A 2010, 1217 2342.

19. Rezaee, M.; Yamini, Y.; Shariati, S.; Esrafili, A.; Shamsipur, M.; J. Chromatogr. A 2009, 1216, 1511.

20. Mashayekhi, H. A.; Abroomand-Azar, P.; Saber-Tehrani, M.; Waqif, S. H.; Chromatographia 2010, 71, 517.

21. Mashayekhi, H. A.; Abroomand-Azar, P.; Saber-Tehrani, M.; Waqif, S. H.; Int. J. Environ. Anal. Chem. 2011, 91, 516.

22. Mashayekhi, H. A.; Rezaee, M.; Sadeghi Garmaroudi, S.; Montazeri, N.; Ahmadi, S. J.; Anal. Sci. 2011, 27, 865.

23. Veyseh, S.; Niazi, A.; Talanta 2016, 147, 114.

24. Maruyama, S. A.; Palombini, S. V.; Claus, T.; Carbonera, F.; Montanher, P. F.; Souza, N. E.; Visentainer, J. V.; J. Braz. Chem. Soc. 2013, 24, 1520.

25. Rocha, D. G.; Santos, F. A.; Augusti, R.; Faria, A. F.; J. Braz. Chem. Soc. 2016, 27, 1.

26. Azizi, S. N.; Asemi, N.; J. Environ. Sci. Health, Part B 2012, 47, 692 .

27. Zhu, S.; Hong, M.; Liu, C.; Pei, Y.; Pharm. Dev. Technol. 2009, 14, 642 .

28. Box, G. E. P.; Hunter, W. G.; Hunter, J. S.; Statistics for Experimenters; Wiley: New York, USA, 1978.

29. Bas, D.; Boyaci, I. H.; J. Food Eng. 2007, 78, 836.
30. Gabrielsson, J.; Trygg, J.; Crit. Rev. Anal. Chem. 2006, 36, 243.

31. Niazi, A.; Jameh-Bozorghi, S.; Nori-Shargh, D.; J. Hazard. Mater. 2008, 151, 603.

32. Niazi, A.; Sharifi, S.; Amjadi, E.; J. Electroanal. Chem. 2008, $623,86$.

33. Krishnan, A.; Williams, L. J.; McIntosh, A. R.; Abdi, H.; NeuroImage 2011, 56, 455.

34. Dyar, M. D.; Carmosino, M. L.; Breves, E. A.; Ozanne, M. V.; Clegg, S. M.; Wiens, R. C.; Spectrochim. Acta, Part B 2012, $70,51$.

35. Bro, R.; Chemom. Intell. Lab. Syst. 1997, 38, 149.

36. Beebe, K. R.; Kowalski, B. R.; Anal. Chem. 1987, 59, 1007A.

37. Andersson, C. A.; Chemom. Intell. Lab. Syst. 1999, 47, 51.

38. Fearn, T.; Chemom. Intell. Lab. Syst. 2000, 50, 47.

39. Wold, S.; Antii, H.; Lindgren, F.; Ohman, J.; Chemom. Intell. Lab. Syst. 1998, 44, 175.

40. Ghasemi, J.; Niazi, A.; Talanta 2005, 65, 1168.

41. Niazi, A.; Yazdanipour, A.; J. Hazard. Mater. 2007, 146, 421.

42. Niazi, A.; Azizi, A.; Ramezani, M.; Spectrochim. Acta, Part A 2008, 71, 1172.

43. Gao, L.; Ren, S.; Chemom. Intell. Lab. Syst. 2010, 100, 57.

44. Hantao, L. W.; Aleme, H. G.; Passador, M. M.; Furtado, E. L.; Ribeiro, F. A. L.; Poppi, R. J.; Augusto, F.; J. Chromatogr. A 2013, 1279, 86.

45. Wold, S.; Trygg, J.; Berglund, A.; Antii, H.; Chemom. Intell. Lab. Syst. 2001, 58, 131.

46. Zeini Jahromi, E.; Bidari, A.; Assadi, Y.; Milani, M. R.; Jamali, M. R.; Anal. Chim. Acta 2007, 585, 305.

47. Kim, H. K.; Kim, J. G.; Hong, J. W.; Polym. Test. 2002, $21,417$.

48. Zhou, Y.; Song, J. Z.; Choi, F. F.; Wu, H. F.; Qiao, C. F.; Ding, L. S.; Gesang, S. L.; Xu, H. X.; J. Chromatogr. A 2009, 1216, 7013.

49. Niazi, A.; Khorshidi, N.; Ghaemmaghami, P.; Spectrochim. Acta, Part A 2015, 135, 69.

50. Vakh, C.; Pochivalov, A.; Andruch, V.; Moskvin, L.; Bulato, A.; Anal. Chim. Acta 2016, 907, 54.

51. Yan, H.; Wang, H.; Qin, X.; Liu, B.; Du, J.; J. Pharm. Biomed. Anal. 2011, 54, 53.

52. Haaland, D. M.; Thomas, E. V.; Anal. Chem. 1990, 62, 1091.

53. Lorber, A.; Faber, K.; Kowalski, B. R.; Anal. Chem. 1997, 69 , 1620 .

54. Ghasemi, J.; Niazi, A.; Anal. Chim. Acta 2005, 533, 169.

55. Goicoechea, H. C.; Olivieri, A. C.; Trends Anal. Chem. 2000, 19, 599.

56. Amraei, A.; Niazi, A.; Alimmoradi, M.; Iran. Chem. Commun. 2017, 5, 207

Submitted: January 29, 2017

Published online: May 4, 2017 